\title{
DIMENSÕES DE GENERO NO PROGRAMA MULHERES MIL
}

\author{
Talita Rafaele D’Agostini Mantovani, Érika Porceli Alaniz
}

Universidade do Oeste Paulista - UNOESTE. Programa de Mestrado em Educação, Presidente Prudente - SP. E-mail: talita.mantovani@ifpr.edu.br

\section{RESUMO}

Resignado à política neoliberal, o Brasil vem adotando vertentes do neoliberalismo, tornando as políticas governamentais atreladas ao capital financeiro internacional. Nessa lógica são criados programas destinados a um público específico, o que atende a um dos pressupostos da reestruturação dos programas sociais na atualidade: a focalização. O objetivo deste trabalho é verificar algumas políticas públicas voltadas às mulheres brasileiras nos últimos dez anos, destacando a influencia dos organismos internacionais na elaboração destas políticas. A metodologia utilizada para isto será a revisão bibliográfica de documentos, leis e artigos relacionados. Um programa em destaque no atual governo é o Programa Mulheres Mil visando promover a qualificação profissional e promover ou ampliar a geração de renda das mulheres. Esse tipo de política, direcionada, para um público selecionado está pautada no ideário neoliberal de que o Estado deve estar presente "apenas residualmente" atendendo emergencialmente aos setores mais pobres da sociedade (DRAIBE, 1993, p. 97).

Palavras-chave: Políticas Públicas. Programa Mulheres Mil. Gênero. Focalização. Organismos Internacionais.

\section{GENDER DIMENSIONS OF PROGRAMA MULHERES MIL}

\begin{abstract}
Resigned to neoliberal policy, Brazil has adopted aspects of neoliberalism, making government policies linked to international finance capital. Focusing: this logic programs to a specific audience, which meets one of the assumptions of the restructuring of social programs today are created. The objective of this work is to verify some public policies aimed at Brazilian women in the last ten years, highlighting the influence of international organizations on drafting these policies. The methodology used for this will be a literature review of documents, laws and related articles. A program highlighted in the current government is the Programa Mulheres Mil to promote vocational skills and promote or enhance the income generation of women. This type of policy, directed to a selected audience is guided by the neoliberal ideology that the state must be present "only residually" an emergency meeting to the poorest sectors of society (DRAIBE, 1993, p. 97th). Keywords: Public Policy. Thousand Women Program. Genre. Focus. International Organizations
\end{abstract}




\section{INTRODUÇÃO}

A expansão da participação do segmento feminino no cenário político brasileiro torna evidente a necessidade de se estudar as alterações das políticas públicas de qualificação profissional que visam o acesso da mulher ao mundo do trabalho. Buscando compreender as dimensões de gênero na qualificação profissional nos governos Lula e Dilma, o presente trabalho traz em sua primeira parte considerações sobre a reforma da educação profissional, bem como a influência exercida pelos organismos internacionais nestas políticas de qualificação profissional. Em seguida, discute-se a questão de gênero nas políticas públicas atuais, com ênfase ao Programa Mulheres Mil.

A relevância deste estudo se dá em primeiro momento por estas políticas públicas se apresentarem como uma das ações estratégicas do atual governo. Por assumir papel de destaque, as políticas públicas para as mulheres são alvo da ênfase nas ações dos governos. Dentro desta perspectiva, é possível que se verifique a tendência das políticas públicas atender um segmento específico da sociedade. Ante a grande relevância que o discurso da qualificação profissional tem tomado na contemporaneidade, o trabalho que se apresenta busca discutir as mediações que se estabelecem entre a atuação dos organismos internacionais, diante da política neoliberal, e a formação propiciada às mulheres. Esta pesquisa destina-se a verificar algumas políticas públicas voltadas às mulheres brasileiras nos últimos dez anos, destacando a influencia dos organismos internacionais na elaboração destas políticas, mediante as orientações do neoliberalismo.

\section{Reforma da educação profissional e atuação dos organismos internacionais}

No Plano Plurianual - PPA (BRASIL, 2011c, p.29) do atual governo da presidente Dilma Rousseff, denominado Plano Mais Brasil, podemos perceber a ênfase dada à educação profissional e tecnológica, sendo esta política de expansão tratada como uma continuidade das ações do governo Lula. Neste documento, salienta-se a importância destas políticas que "vêm contribuindo para a ampliação da escolaridade e formação dos jovens às quais se integrarão outras, no governo da Presidenta Dilma, como o Pronatec (Programa Nacional de acesso ao Ensino Técnico e Emprego) e o Plano Brasil Sem Miséria" (BRASIL, 2011a, p.01).

Esta franca expansão da educação profissional, tem como pretexto a necessidade da mão de obra especializada, inerente ao desenvolvimento do modo de produção capitalista, quando no PPA é explicitada a necessidade da formação de trabalhadores para atender as demandas do mercado: 
Outro aspecto fundamental e que constitui condição para a convergência de condições econômicas e sociais entre as regiões, acompanhada da tendência à interiorização, é a educação, determinante para a inclusão social, a efetivação de direitos, a inovação, as atividades econômicas intensivas em conhecimento e a formação de mão de obra nos vários níveis (BRASIL, 2011c, p.61).

Esta tendência percebida no documento governamental está em consonância com a construção de um novo cenário mundial em que se encontra a educação profissional, que têm levado muitos países a reformarem suas políticas educacionais. Estas reformas são defendidas com o pretexto de aumentar a produtividade dos trabalhadores a fim de enfrentar a competição internacional em condições menos desvantajosas, conforme aponta Cunha, (2000, p. 48). O Brasil tem seguido estas indicações buscando a especialização de segmentos da população através da educação profissional.

Em 2004, no início do Governo Lula, a reconstrução da política pública para a educação profissional é indicada no documento publicado pela SETEC (Secretaria de Educação Profissional e Tecnológica), chamado 'Políticas Públicas para a Educação Profissional e Tecnológica' (POLÍTICAS, 2013), constando a necessidade da criação de mecanismos de controle destas políticas e da definição de competências e responsabilidades dos entes federativos para a educação profissional.

No ínterim da reforma da educação profissional, no governo Lula, houve a expansão da rede federal de educação tecnológica, que se institucionalizou por meio da criação, em 2008, dos Institutos Federais de Educação Profissional e Tecnológica. Criados pela Lei Federal no 11.892 de 29 de dezembro de 2008 (BRASIL, 2008a), os Institutos Federais de Educação, Ciência e Tecnologia (IFs) têm por finalidade e característica promover educação profissional e tecnológica em todos os seus níveis e modalidades, formando e qualificando cidadãos com vistas à qualificação profissional. Além disso, a lei de criação apresenta como finalidade a realização de cursos de formação inicial e continuada para trabalhadores, bem como a certificação de competências profissionais e o desenvolvimento de atividades de extensão em articulação com o mundo do trabalho e segmentos sociais (BRASIL, 2008a, p.06). Dessa forma, o papel atribuído aos IFs o qualifica como instituição executora e gestora de políticas públicas para a educação profissional e tecnológica.

Neste sentido, um conjunto de políticas públicas para qualificação de trabalhadores está sendo criada pelo governo visando ampliar o acesso da população à educação profissional, atendendo, assim, as demandas do mercado capitalista. 
Entre os programas profissionalizantes de destaque temos o Programa Mulheres Mil (PMM). Este programa foi lançado inicialmente como projeto piloto nas regiões Norte e Nordeste do país. As atividades iniciaram-se em 2005 e em 21 de julho de 2011, através da Portaria no 1015 (BRASIL, 2011b), o Projeto Mulheres Mil é instituído como Programa Nacional, constituindo-se em uma das ações do Plano Brasil Sem Miséria.

O Plano Brasil Sem Miséria, como consta em seu decreto de criação, tem como finalidade superar a situação de extrema pobreza da população em todo o território nacional, por meio da integração e articulação de políticas, programas e ações. São eixos de atuação do Plano Brasil Sem Miséria: 1) garantia de renda; 2) acesso a serviços públicos e 3) inclusão produtiva (BRASIL, 2011a). O objetivo desses programas é promover a qualificação profissional para melhorar a inserção no mundo do trabalho e, consequentemente, a renda. Estão inseridos neste eixo, o Pronatec e o PMM (BRASIL, 2012).

\section{Questão de Gênero no Programa Mulheres Mil}

A exemplo das diretrizes contidas no PMM observa-se, no Brasil, uma crescente implantação de políticas públicas voltadas para as mulheres, estratégia que vem de encontro as orientações internacionais e a proposta de focalização do ideário neoliberal.

Conforme discute Draibe (1993, p. 97) a reestruturação dos programas sociais preconizada pelo neoliberalismo se dá através da descentralização, privatização e focalização destes programas. Segundo a autora, a "focalização significa o direcionamento do gasto social a programas e a públicos-alvo específicos, seletivamente escolhidos pela maior necessidade e urgência" (Draibe, 1993, p.97). Ao concentrar esforços em ações voltadas para o gênero feminino, observa-se a aplicação da focalização como característica da agenda neoliberal para as políticas públicas, o que culmina em grande número de projetos e programas direcionados para as mulheres.

Desde o final dos anos de 1970 diversas mobilizações tem acontecido em torno da questão de gênero em todo o mundo. Em 1979 foi adotada pela Assembleia Geral da ONU a Convenção sobre a Eliminação de Todas as Formas de Discriminação Contra as Mulheres (CEDAW). Os documentos gerados por esta convenção são descritos como uma declaração internacional dos direitos das mulheres.

O governo brasileiro tem trabalhado com o intuito de implantar uma série de políticas voltadas para as mulheres, tendo assim, portanto, cumprido os pressupostos da Convenção sobre a Eliminação de Todas as Formas de Discriminação Contra as Mulheres (CEDAW). No ano de 2003 
o então presidente Luiz Inácio Lula da Silva criou a Secretaria de Políticas para as Mulheres (SPM) através da Lei no 10.683 de 28 de maio de 2003 (BRASIL, 2003), que dispõe sobre a organização da Presidência da República e dos Ministérios. No entanto a competência desta Secretaria foi definida somente em 2010, através da Lei no 12.314, que altera a Lei anterior.

Art. 22. À Secretaria de Políticas para as Mulheres compete assessorar direta e imediatamente o Presidente da República na formulação, coordenação e articulação de políticas para as mulheres, bem como elaborar e implementar campanhas educativas e antidiscriminatórias de caráter nacional, elaborar o planejamento de gênero que contribua na ação do governo federal e demais esferas de governo, com vistas na promoção da igualdade, articular, promover e executar programas de cooperação com organismos nacionais e internacionais, públicos e privados, voltados à implementação de políticas para as mulheres, promover o acompanhamento da implementação de legislação de ação afirmativa e definição de ações públicas que visem ao cumprimento dos acordos, convenções e planos de ação assinados pelo Brasil, nos aspectos relativos à igualdade entre mulheres e homens e de combate à discriminação, tendo como estrutura básica o Conselho Nacional dos Direitos da Mulher, o Gabinete, a Secretaria-Executiva e até 3 (três) Secretarias (BRASIL, 2010).

Através do Decreto no 8.030, de 20 de junho de 2013, já no governo Dilma, foram definidas as secretarias que compunham a SPM, sendo elas, a Secretaria de Políticas do Trabalho e Autonomia Econômica das Mulheres (SAE); Secretaria de Enfrentamento à Violência contra as Mulheres (SEV); e Secretaria de Articulação Institucional e Ações Temáticas. Além das Secretarias, fazem parte da SPM o Conselho Nacional dos Direitos da Mulher, que antes era vinculado ao Ministério da Justiça e em 2003 passou a integrar a estrutura da SPM. Todas estas instâncias são responsáveis por formular e coordenar políticas voltadas às mulheres conforme o planejamento governamental, atuando também no plano internacional, atuando em diferentes foros de importantes organismos, tais como a ONU, Organização dos Estados Americanos (OEA) e Mercosul.

Um dos documentos norteadores das políticas públicas para as mulheres é o Plano Nacional de Políticas para as Mulheres (PNPM), que está em sua segunda versão. O objetivo é que o PNPM seja adotado pelos governos federal, estaduais e municipais, bem como pelos movimentos sociais, como um instrumento de trabalho. Dessa forma, no executivo federal, as políticas públicas passam a ser orientadas pelo Plano Nacional de Políticas para as Mulheres (PNPM), desdobradas nos estados e municípios pelos organismos governamentais de políticas para as mulheres (BRASIL, 2004).

Assim como no governo anterior, no governo Dilma (2011 a 2013) também se pode observar a influência das orientações internacionais para a educação e o trabalho em planos 
governamentais, como a publicação do Plano Brasil Sem Miséria, instituído pelo Decreto no 7.492 de 02 de junho de 2011. Este plano tem por objetivos elevar a renda per capita da população em situação de extrema pobreza; ampliar o acesso à serviços públicos e propiciar o acesso à população em situação de extrema pobreza a oportunidades de ocupação e renda, por meio de ações de inclusão produtiva (BRASIL, 2011a). Este plano originou várias ações a nível federal, como o programa Brasil Carinhoso, e reuniu, sobre o mesmo decreto, programas já existentes e de grande importância governamental, como o Bolsa-Família (BRASIL, 2012).

No campo educacional, a inclusão produtiva, descrita no Plano Brasil Sem Miséria se dá através de programas específicos como o PMM.

Corroborando com a agenda neoliberal, no ano 2000 a Organização das Nações Unidas promulgou a Declaração do Milênio. Entre as metas estabelecidas estão a erradicação da extrema pobreza e da fome, promoção da igualdade entre os sexos, autonomia das mulheres e garantia da sustentabilidade ambiental. O empoderamento das mulheres é importante para o cumprimento de objetivos ligados a pobreza, fome, saúde e educação (PNUD, 2012).

Mais recentemente, no ano de 2010 a Assembleia Geral da ONU - Organização das Nações Unidas - votou por unanimidade a criação de um órgão único da ONU encarregado de acelerar os processos para alcançar a igualdade de gênero e fortalecer a autonomia das mulheres, uma entidade para a Igualdade de Gênero e o Empoderamento das Mulheres, chamada ONU Mulheres. Segundo consta no site da ONU (ONU, 2013)

a ONU Mulheres trabalha com as premissas fundamentais de que as mulheres e meninas ao redor do mundo têm o direito a uma vida livre de discriminação, violência e pobreza, e de que a igualdade de gênero é um requisito central para se alcançar o desenvolvimento.

Os programas e ações voltados para as mulheres, em especial no que concerne a educação, são formas compensatórias para aliviar as possíveis tensões no setor social e inseri-las no mercado consumidor.

Embora a orientação de focalizar as mulheres como beneficiárias de políticas públicas esteja presente nos documentos mais recentes dos organismos multilaterais não é um episódio isolado do conjunto de políticas acordadas entre esses organismos e o Estado brasileiro, principalmente a partir da década de 1990, com o documento intitulado "Para além do consenso de Washington", em que o BM destaca-se como o principal protagonista nos acordos internacionais com a América Latina. A esse respeito, Fonseca (1995) traz uma série de considerações sobre a influência do BM no setor educacional brasileiro. Conforme análise desta 
pesquisadora, em documentos do BM, os empréstimos aos países de baixa renda privilegiam, primeiramente, os programas de baixo custo para o ensino fundamental, a fim de prover instrução básica para crianças e mulheres.

No entendimento do BM o nível básico de ensino contribuiria para maior aceitação, por parte das mulheres, aos programas de controle da natalidade, bem como seriam um estímulo à intensificação de sua participação na vida produtiva. Segundo a agência, a contenção demográfica seria necessária para a preservação dos recursos naturais e para a melhoria da saúde feminina e da situação econômica familiar, visto que o aumento da taxa demográfica incrementaria a pobreza (FONSECA, 1998). Observamos que estes temas estão presentes em políticas públicas para as mulheres até os dias de hoje, a exemplo do que ocorre no PMM, disciplinas como noções de saúde da mulher, relações humanas e educação ambiental fazem parte do conteúdo básico do programa, em preparação para a profissionalização.

Assim como as demais políticas voltadas às mulheres, o PMM se enquadra no pressuposto neoliberal da focalização, ao tratar especificamente do segmento feminino. Enquanto as ações governamentais planejadas pela SPM visam à diminuição da discriminação e da violência e o aumento da participação feminina na busca por seus direitos e na vida política, o PMM possui enfoque prioritariamente profissionalizante, o aspecto da inserção profissional é a principal alvo do programa.

\section{CONSIDERAÇÕES FINAIS}

A questão de gênero se mostra como central nas políticas públicas atuais; observamos que grande número de políticas para as mulheres foram criadas nos dois últimos governos brasileiros. Este fato se deve, principalmente, devido às orientações internacionais para erradicação da pobreza e aumento da escolaridade das mulheres, com vistas à inserção econômica das mulheres e ao controle demográfico, almejando o controle da pobreza.

Neste cenário o PMM desponta como uma política de qualificação profissional de destaque no atual governo, uma vez que reúne em si aspectos de cidadania, educação e principalmente a inserção profissional, com vistas a atender as orientações neoliberais.

\section{REFERENCIAS}

BRASIL. Lei $\mathbf{n} \mathbf{1} \mathbf{1 0 . 6 8 3}$ de $\mathbf{2 8}$ de maio de 2003. Disponível em: http://www.planalto.gov.br/ccivil_03/leis/2003/l10.683.htm>. Acesso em 15 jun. 2014. 
BRASIL. Presidência Da República. Secretaria Especial De Políticas para as Mulheres. Plano Nacional de Políticas para as Mulheres. 2004. 104p.

BRASIL. Ministério da Educação. Lei no 11.892, de 29 de dezembro de 2008a. Disponível em: <http://www.planalto.gov.br/ccivil_03/_ato2007-2010/2008/lei/l11892.htm> Acesso em: 29 abr. 2013.

BRASIL. Lei no 12.314 de 19 de agosto de 2010. Disponível em: < http://www.planalto.gov.br/ccivil_03/_ato2007-2010/2010/lei//12314.htm>. Acesso em 15 jun. 2014.

BRASIL. Ministério do Desenvolvimento Social e Combate à Fome. Plano Brasil Sem Miséria. Decreto no 7.492 de 02 de junho de 2011a. Disponível em: <http://www.planalto.gov.br/ccivil_03/_Ato2011-2014/2011/Decreto/D7492.htm> Acesso em: 30 abr. 2013.

BRASIL. Ministério da Educação. Portaria no 1.015 de 21 de julho de 2011b. Disponível em: <http://www.mds.gov.br/brasilsemmiseria/legislacao-2/legislacao/arquivos/portaria-mulheresmil-n-1015.pdf.> Acesso em: 28 nov. 2011.

BRASIL. Ministério do Planejamento, Orçamento e Gestão. Plano Plurianual 2012-2015. Brasília, 2011c. Disponível em:

<http://www.planejamento.gov.br/secretarias/upload/Arquivos/spi/PPA/2012/mensagem_presid encial_ppa.pdf.> Acesso em: 30 abr. 2013.

BRASIL. Revista um ano de resultados do Plano Brasil sem miséria. 2012. Disponível em: <http://www.brasilsemmiseria.gov.br/documentos> Acesso em: 03 ago. 2012.

BRUNO, L. Educação e desenvolvimento econômico no Brasil. Revista Brasileira de Educação, v. 16, n. 48, p. 545-562, set.-dez. 2011. http://dx.doi.org/10.1590/S1413-24782011000300002

CUNHA, L. A. Ensino Médio e Ensino Técnico na América Latina: Brasil, Argentina e Chile. Cadernos de Pesquisa, n.111, p.47-70, dez. 2000.

DRAIBE, S. M. As políticas sociais e o neoliberalismo: reflexões suscitadas pelas experiências latinoamericanas. Revista USP, São Paulo, n.17, p.86-101, 1993.

FONSECA, M. O Banco Mundial como referência para a justiça social no terceiro mundo: evidências do caso brasileiro. Revista da Faculdade de Educação. [online]. 1998, vol.24, n.1, pp. 37-69. ISSN 0102-2555.

GUIA METODOLÓGICO DO SISTEMA DE ACESSO, PERMANÊNCIA E ÊXITO. Programa Mulheres Mil. Disponível em http://portal.mec.gov.br/index.php?option=com_content\&view=article\&id=12299:programamulheres-mil-\&catid=267:programa-mulheres-mil-\&ltemid=602. Acesso em: 02 maio 2013.

ONU - Organização das Nações Unidas. A ONU e as mulheres. Disponível em $<$ http://www.onu.org.br/a-onu-em-acao/a-onu-e-as-mulheres/>. Acesso em 06 de novembro de 2013. 
POLÍTICAS PÚBLICAS PARA A EDUCAÇÃO PROFISSIONAL E TECNOLÓGICA. Disponível em:

<http://portal.mec.gov.br/setec/arquivos/pdf/p_publicas.pdf.> Acesso em: 02 maio 2013.

PNUD - PROGRAMA NAÇÕES UNIDAS PARA O DESENVOLVIMENTO NO BRASIL. Os Objetivos de Desenvolvimento do Milênio. Disponível em <http://www.pnud.org.br/ODM.aspx>. Acesso em: 23 ago. 2012. 